because of the small bulk patients prefer this to cortical extracts. Further, deoxycortone can be implanted subcutaneously, one tablet of $100 \mathrm{mg}$. being used for each $1 \mathrm{mg}$. of injected material. Thus the average patient receiving $5 \mathrm{mg}$. daily would have implanted $500 \mathrm{mg}$. of deoxycortone tablets (five tablets of $100 \mathrm{mg}$. each). Before calculating this dosage it is advisable to maintain the patient for several weeks on injections, as the ultimate daily maintenance dosage may be appreciably less than the initial dosage.

As the effects of overdosage are severe and potentially fatal, I subtract $100 \mathrm{mg}$. from my calculated implantation dose, and for further safety I rarely do an initial implantation of more than $300 \mathrm{mg}$. The implantation calculations I have given are the ones I initially recommended, but are only half of the equivalents given by an American authority.

The effects of overdosage are seen both with the injection method and with the implantation method, but the former is much easier to correct than the latter, which necessitates removal of tablets. Overdosage leads to excessive retention of fluid and sodium, with increased excretion of potassium and low potassium serum concentration, resulting in weakness and paralysis of muscles, including the cardiac muscle. Other characteristic manifestations are superficial oedema of face and limbs, crepitations in the lungs, and enlargement of the heart, with or without pericardial effusion. The oedema, however, may not be conspicuous, and the excessive weakness or paralysis may be wrongly regarded as due to inadequate treatment. The blood chemistry may be deceptive in that the sodium and chloride may be normal, but the serum potassium is always low-for example, $12 \mathrm{mg}$. per $100 \mathrm{ml}$. Hypertension may be present initially with excessive fluid retention, but with cardiac failure this gives place to hypotension. Apart from the oedema of the cardiac muscle, multiple foci of necrosis in the heart have been found at necropsy. Electrocardiographic changes, with low serum potassium, are low-voltage QRS complexes, lowering or inversion of the $T$ waves, depression of the S-T segment, and prolongation of the QRS interval. Occasionally some patients show a more insidious chronic dry hypertension with this treatment, but in the absence of the other features this is not usually important and may tend to correct itself. (Such low potassium concentrations are also met with in diabetic coma treated with intravenous salines and glucose, in infantile diarrhoea, and in surgical operations where there have been diarrhoea, intestinal drainage, and/or excessive intravenous saline.)

The best treatment of overdosage in Addison's disease is removal of the implanted tablets, but as a preliminary emergency measure $100 \mathrm{ml}$. of $2 \%$ potassium chloride may be injected intravenously. If the dosage is properly calculated, however, implantation therapy is excellent, and since the effects last some eight months many patients prefer it to all other methods of treatment. As the effect of therapy wears off the administration of salt by mouth may permit the postponement of further implantation from the sixth to the tenth month. Salt is also given by mouth without any other therapy in mild cases of Addison's disease. The dosage is up to $12 \mathrm{~g}$. daily (three teaspoonfuls) in divided doses in a tumblerful of water or lime juice, or with porridge or potatoes. A mixture of sodium chloride, phosphate, citrate, and bicarbonate may prove more palatable. Sodium chloride in 1-g. capsules can also be obtained. Additional salt should be given with caution if deoxycortone is also used, for fear of excessive water and salt retention.

Such overdosage effects of deoxycortone as described above are not usually met with if cortical extracts are used, especially if the daily dose of the latter is less than $20 \mathrm{ml}$.
In the U.S.A. a concentrated lipoid-extract of hog's adrenals has been prepared which is five times as potent as an aqueous extract, particularly in regard to the effect on carbohydrate metabolism. The extract is not yet available in this country. Linguets of adrenal cortical extracts for dissolving under the tongue, as prepared for some American investigators, have proved adequate for prolonged therapy, but those available to me have not proved sufficiently constant in action. Testosterone or methyl testosterone is indicated where the urinary 17 -ketosteroids are less than $5 \mathrm{mg}$. a day, but if implanted the augmentation thereby of the sodium and fluid retention of deoxycortone must be reckoned with. In crisis, or in the acute phase of adrenal insufficiency, treatment differs from the more chronic phase only in its intensity and the advisability of using both cortical extract and deoxycortone. Intravenous saline is called for if the patient has been allowed to become very collapsed, and it is often necessary to cut down on a vein, If severe hypoglycaemia is suspected-and this is more likely in a patient who has been treated previously with deoxycortone and not cortical extract-intravenous glucose is necessary.

\section{Course and Prognosis}

Even if adequately treated, as judged by biochemical data, the more severe cases of Addison's disease lead a precariously balanced existence, and are liable to go into crisis, with or without a precipitating cause-for example, infection, trauma, strain - and to have phases of hypoglycaemia, sometimes acute and dramatic. They tend to lose weight and body fat over a period of years, and the pubic and axillary hair may become thinned. Apathy and inertia are not infrequent, and there is often a sensitivity to cold and infection. Nevertheless, one of my patients had two successful pregnancies under treatment, and is a good mother to the children and an efficient wife. Another seemed to have a sustained remission during her climacteric, and then partially relapsed again.

\section{BRONCHOSPIROMETRY}

\section{SEMON LECTURE BY DR. PAUL FRENCKNER}

The annual Semon Lecture was delivered at the Royal Society of Medicine on November 2 by Dr. Paul Frenckner, of the Karolinska Institutet, Stockholm. His subject was "The Development and Present Use of Bronchospirometry." Dr. E. R. Boland, Dean of the Faculty of Medicine, London University, was in the chair.

Dr. FRENCKNER began with a tribute to Sir Felix Semon, whom he described as one of the greatest laryngologists of all time, with whose work and discoveries, he said, he had come into contact in his own first laryngological studies, on paralysis of the vocal cord, 25 years ago.

Dr. Frenckner described his first experiments in 1929 in what he called bronchial catheterization. His purpose was to work out a method of clinical examination with which it would be possible to judge the function of each lung separately, in the same manner as it was possible to form an opinion on each kidney by ureteral catheterization. By bronchial catheterization was meant the passing of a tubular instrument, flexible or rigid, into a predetermined bronchus, an airtight closure between the bronchial wall and the instrument being obtained by means of a special fixture at its distal end, so that it was possible to transmit to or from the area of distribution of the airway in question a gaseous or fluid substance for diagnostic or therapeutic purposes. In association with Jacobaeus and others in Sweden the concept of bronchospirometry was created. Various instruments had been used during the development of the investigation, but the work took a big step forward with the introduction of Carlens's 
double catheter, which was made of rubber of about the same rigidity as the ordinary urethral catheter. This was introduced, without fluoroscopy, under mirror guidance over a curved metal stylet.

\section{Investigation of Miners' Lungs}

The lecturer went on to describe an investigation on the labourers at certain gold and copper mines, who were much exposed to arsenic fumes and sulphur dioxide. Despite protective arrangements, these workers showed pronounced atrophy of the respiratory tract mucous membrane from the nose to the bronchi. The object of the spirometric examination was to ascertain whether there was any disturbance of pulmonary function which could be ascribed to emphysema or epithelial damage, and, if so, whether both lungs showed the same degree of impaired function. Dr. Frenckner gave an account of the results from the 75 cases so far examined.

Carlens's rubber catheter was introduced under local analgesia and attached to an oxygen-filled double spirometer. The recording went on for eight minutes while the subject breathed with maximal inspiration and expiration; forced breathing followed for a quarter or half a minute, and then the residual air was determined. The volumetric values of particular interest were those indicating total capacity, vital capacity, and oxygen consumption. Variations in the total capacity for each lung were often considerable. The average value in the cases taken was $2,600 \mathrm{ml}$. for the right lung and 2,400 for the left, but this average was found in only a small percentage of the cases, and there were deviations of as much as $500 \mathrm{ml}$. above or below. Impaired function of one or both lungs was demonstrated in a number of cases.

The vital capacity values were on the average very much below normal, and some of the deviations were considerable. The oxygen absorption was also noted, and, in the cases where it was low on the spirometer reading, bronchoscopy showed the mucous membrane to be extremely atrophic, although, owing to some other observations, he was unwilling to admit at present more than a suspicion that atrophy and poor oxygen consumption might be related. His general conclusion was that the recorded values for oxygen consumption might possibly indicate decreased lung function, which in certain of the cases was considerably more pronounced in one lung than in the other. It was possible that this decreased oxygen absorption might be due to epithelial damage.

\section{Exchange of Respiratory Gases}

Estimation of the respiratory gas exchange had been made with the help of the "residual quotient," the "equilibrium quotient," and the "ventilation equivalent" at rest and on forced breathing, in addition to oxygen consumption. The residual quotient ( $\left.\frac{\text { residual air }}{\text { total lung capacity }}\right)$ showed high values throughout, indicating a decreased lung function with poor emptying ability. In some few cases the difference between right and left lungs was marked, probably indicating unilateral damage. The most likely cause of the impaired function was emphysema, but epithelial damage caused by poisonous gases could not be excluded.

The equilibrium quotient ( $\left.\frac{\text { supplemental air }+ \text { residual air }}{\text { total lung capacity }}\right)$ in the majority of cases was within normal limits, the increased residual air values being compensated by very low values for the supplemental air. The ventilation equivalent in this investigation had been calculated according to the formula

minute ventilation

oxygen consumption $/ \mathrm{min}$. $\times 10$, and should be the mos important factor in estimating the condition of the alveolar epithelium. The values obtained indicated that the alveolar epithelium had been damaged and that the damage had affected the right and left lungs unequally.

\section{Routine Examination in Lung Disease}

Dr. Frenckner said that bronchospirometry was also useful in the routine investigation of certain lung diseases. It was often helpful to be able to estimate the oxygen consumption, and to determine the residual quotient and ventilation equivalent, of each lung separately, particularly in cases where operation or irreversible collapse therapy was likely to be performed.

Finally the lecturer spoke of a new method of recording which would permit of a more careful analysis of the breathing phases. The ingoing and outgoing air from each lung was passed over a small sensitive antenna made of the finest platinum wire. This wire was in an electric circuit, and, on being cooled by the passage of air, variations in voltage took place, and were registered by an oscillograph. Interesting details were brought out in the curves obtained. Delay in one lung might be recorded with precision to $0.1 \mathrm{sec}$. Inhalation and exhalation gave typical recordings, and certain diseases such as asthma appeared to have characteristic curves.

Dr. Frenckner said that he himself was not a lung physiologist ; his purpose was to find a method of clinical examination which would make it possible to appraise the functional capacity of the lungs under normal and pathological conditions. Apparatus was still far from perfect and needed to be critically tested and improved.

The lecture, which was followed by a film, was greatly appreciated by the large audience of laryngologists and others assembled.

\section{OPENING OF THE NEW LABORATORIES OF THE PNEUMOCONIOSIS RESEARCH UNIT}

\author{
[By a Special Correspondent]
}

The new research laboratories of the Medical Research Council's Pneumoconiosis Research Unit at Llandough Hospital, near Cardiff, were opened by Mr. Herbert Morrison, the Lord President of the Council, on October 28.

This Unit was set up by the Medical Research Council in 1945 at the request of the Ministry of Fuel and Power to investigate coal-miners' pneumoconiosis. Dr. C. M. Fletcher was appointed director of the Unit, and the staff now consists of 12 medical and 8 non-medical scientists, with their technical and administrative assistants.

The new building, designed by Mr. A. Steele, A.R.I.B.A.-at the time chief architect to the Cardiff Corporation-and constructed under the supervision of Mr. G. Griffiths, A.R.I.B.A., houses the whole Unit with the exception of a pathologist working under Professor J. Gough in the Department of Pathology of the Welsh National School of Medicine. It is a long single-story building with a flat roof, connected to Llandough Hospital by a covered way. The windows are arranged in long continuous strips extending over several rooms to give the maximum amount of light. The building comprises 37 laboratories, 18 offices, $x$-ray and out-patient departments, animal quarters, dark-rooms, workshops, stores, garage, kitchen and refectory, and a large conference room also used as a library There are some 90 rooms in all. Both sides of the north corridor are devoted to laboratories for the study of the concentration and composition of airborne dusts by chemical, physicochemical, and petrological methods. There is also a large laboratory containing a wind tunnel in which artificial dust clouds may be generated for the testing of dust-sampling apparatus. The physiological laboratories are at the west end of the south corridor with the administrative block and conference room in the centre, and the offices of the epidemiological section are at the eastern end of the same corridor. There are five basement rooms containing a photographic department, a constanttemperature store-room, and a calorifier which is supplied with steam heat by the hospital.

The Unit also possesses a mobile $x$-ray van and an office van for use in radiological surveys at mines. These are being used at present for a large-scale survey of pneumoconiosis and tuberculosis in the Little Rhondda Valley (Rhondda Fach Scheme). 